\title{
INCIDENCIA DEL PROCESO MONITORIO COMO GARANTÍA DEL DERECHO DE CRÉDITO EN LOS PROCESOS ADELANTADOS EN LOS JUZGADOS CIVILES MUNICIPALES DE SINCELEJO, AÑOS 2016 Y 2017
}

\author{
Jorge Armando Valdelamar Montes ${ }^{1}$ \\ Jaison Sierra Ramírez ${ }^{2}$ \\ Sindry Murillo Calderin ${ }^{3}$
}

\section{Resumen}

El presente artículo presenta los resultados de una investigación Sociojurídica orientada a establecer la incidencia del proceso monitorio sobre el derecho de crédito en los procesos adelantados en los juzgados civiles municipales de Sincelejo. Constituyo un trabajo de tipo descriptivo, realizado bajo un enfoque cualitativo, empleando fuentes secundarias de información, es decir, es un trabajo realizado teniendo como base fuentes documentales. Consta de cuatro partes, en las cuales se abordan los ejes temáticos referidos al derecho de crédito, los procesos monitorios y la conciliación extrajudicial en derecho desde la doctrina, la legislación y la jurisprudencia colombiana. Finalmente se realizó un análisis de las estadísticas de procesos monitorios manejadas por los juzgados civiles municipales de Sincelejo, que permitió observar el comportamiento y uso de esta figura procesal y su incidencia como garantía judicial del derecho de crédito, y los aportes del Consultorio Jurídico de CECAR, en el manejo de estos procesos.

$1 \quad$ Especialista en Derecho Procesal Civil, Conciliador Extrajudicial en Derecho y Abogado. Docente Investigador de la Facultad de Derecho y Ciencias Políticas de CECAR. miembro del Grupo de Investigación GISCER. Email: jorge.valdelamar@cecar.edu. CO

2 Egresado del Programa de Derecho de la Corporación Universitaria del Caribe CECAR. Email: jaison.sierra@cecar.edu.co

3 Candidata a Especialista en Derecho Procesal Civil y Egresado del Programa de Derecho de la Corporación Universitaria del Caribe CECAR. Email: sindri.murillo@ cecar.edu.co 

adelantados en los juzgados civiles municipales de Sincelejo...

Palabras clave: Incidencia, Proceso Monitorio, Garantía, Derecho de Crédito, Juzgados Civiles, Consultorio Jurídico

\section{Abstract}

This article presents the results of a Sociojurídica investigation aimed at establishing the incidence of the monitoring process on the right to credit in the processes carried out in the municipal civil courts of Sincelejo. It constitutes a descriptive type of work, carried out under a qualitative approach, using secondary sources of information, that is to say, it is a work carried out on the basis of documentary sources. It consists of four parts, in which the thematic axes referred to the right of credit, the monitorios processes and the extrajudicial conciliation in right are approached from the doctrine, the legislation and the Colombian jurisprudence. Finally, an analysis was made of the statistics of monitorios processes managed by the municipal civil courts of Sincelejo, which allowed observing the behavior and use of this procedural figure and its incidence as a judicial guarantee of the right to credit, and the contributions of the Legal Clinic of CECAR, in the management of these processes.

Key words: Incidence, Payment Process, Guarantee, Credit Law, Civil Courts, Legal Consulting

\section{Introducción}

Con la entrada en vigencia de la Ley 1564 de 2012 (Código General del Proceso), se introdujeron varias figuras procesales cuya finalidad era dinamizar los procesos e innovar en materia procedimental, a efectos de garantizar una justicia eficiente, eficaz y rápida. Dentro de estas innovaciones, el legislador incorporó el proceso monitorio, cuyo objetivo principal es garantizar el derecho de crédito de un acreedor cuando carece de título ejecutivo para hacer efectiva su obligación en sede judicial. No obstante, dada su naturaleza de proceso declarativo especial, y atendiendo a sus características, teniendo como presente lo preceptuado en el artículo 38 del Código General del Proceso (2012), resulta jurídicamente inquietante analizarlo desde la practica conciliatoria extrajudicial en derecho, ya que como se sabe, ésta se constituye para los procesos de esta naturaleza en requisito de procedibilidad, no obstante, en las excepciones expresamente señaladas en el artículo citado, no se encuentra este tipo de proceso, por lo 
que surge el interrogante sobre la procedencia del mecanismo alternativo de solución de conflictos para los procesos monitorios.

Ahora bien, como quiera que el proceso judicial diseñado por el legislador tiene como objeto la garantía de un derecho sustancial, se hace necesario estudiar la incidencia de éste frente a la protección del derecho de crédito, ya que existen otros procesos en el mismo catalogo normativo con similar función, particularmente. Resulta relevante cuestionarse desde la óptica jurídica esta situación, en una sección del país que se caracteriza por la informalidad de las relaciones civiles y comerciales, afectando de esta manera su derecho de acceso a la tutela judicial efectiva de sus derechos. Por ello, teniendo en cuenta lo anterior, la pregunta sobre la cual gira esta investigación es: ¿Cuál es la incidencia del proceso monitorio como garantía del derecho de crédito en los procesos adelantados en los juzgados civiles municipales de Sincelejo Colombia, desde la práctica del Consultorio Jurídico de CECAR, durante los años 2016 y 2017 ?

En este orden de ideas, consideramos que este trabajo aporta al debate académico y jurídico en cuanto a la temática abordada, en la medida en que ésta sienta bases en el estudio de las diferentes figuras procesales, a través de la recopilación y análisis de información contenida en distintas fuentes bibliográficas y normativas. La presente investigación asume como límite espacial los juzgados civiles municipales de la ciudad de Sincelejo, Colombia, ya que queremos analizar el comportamiento de la figura procesal objeto de estudio, frente a la realidad social y costumbres jurídicas de esta zona del país, que se ha caracterizado, principalmente, por la informalidad en muchas de sus dinámicas. Es por ello que el presente trabajo permitiría hacer un análisis no solo del proceso monitorio y su configuración en el Código General del Proceso, sino que permitirá observar varias posturas académicas, jurídicas y jurisprudenciales sobre la figura del mecanismo alternativo de solución de conflictos, y la incidencia que este tiene sobre la finalidad principal del proceso monitorio, que es la satisfacción del derecho de crédito.

De lo anterior se desprende su relevancia y pertinencia, ya que aporta elementos de juicio para el debate jurídico - procesal que existe en torno a esta temática, y que ha hecho que las Altas Cortes se pronuncien al respecto. Ergo, como el propósito es establecer la incidencia del proceso monitorio como garantía del derecho de crédito en los procesos que se adelantaron en los juzgados civiles municipales de Sincelejo durante los años 2016 y 2017, en un primer momento 

adelantados en los juzgados civiles municipales de Sincelejo...

se realizará un desarrollo conceptual del derecho de crédito. En un momento se hará un abordaje de la figura del proceso objeto de estudio a nivel doctrinal, legal y jurisprudencial, para luego estudiar la figura de la conciliación extrajudicial en derecho en relación con los procesos monitorios, para finalmente hacer un análisis estadístico de esta figura procesal, incluyendo las estadísticas manejadas por el Consultorio Jurídico de CECAR.

\section{Derecho de Crédito en el ordenamiento jurídico colombiano}

Para Enciclopedia Jurídica (2018), el derecho se define como: "el derecho otorgado al titular o legitimado (acreedor) de poder exigir a otra persona de derecho (deudor) una prestación. Esta puede ser de dar, hacer o no hacer."

De la anterior de definición se desprende que este derecho se configura con el establecimiento de una relación jurídica surgida de un negocio jurídico, es decir, de la relación que tiene una persona respecto de otra, en la cual la segunda está obligada con la primera a dar, hacer o no hacer algo (Ternera \& Mantilla, 2018). En suma, la característica fundamental del derecho de crédito está dada por la configuración de la obligación. Esta obligación, de acuerdo a las Institutas de Justiniano, extraídas de la obra de Alterini, Ameal y López (1995), citadas por Jiménez (2013): "Es un vínculo jurídico, de acuerdo con nuestro Derecho Civil que nos constriñe a pagar una cosa (Obligatio est juris vinculum, quo necessitate adstringimur alicujus solvendae rei, secundum nostrae civitates jura)".

De la misma manera, se identifica que esta relación es de carácter prestacional, de acuerdo a sus características, evidenciándose una relación correlativa puesto que, para uno de los integrantes de la relación jurídica, de carácter patrimonial y de temporalidad establecida, se establece un derecho subjetivo de crédito (acreedor), y para el otro se configura un deber jurídico de pagar (deudor) (Jiménez, 2013b).

Ahora, esta concepción de derecho de crédito y de obligación, se origina en las disposiciones normativas de la antigua Roma. En un artículo de investigación, que ya se ha referido en líneas anteriores, el doctrinante Jorge Jiménez Bolaños, publicado por la Revista Judicial de Costa Rica (2013), al hacer un análisis de la evolución de la obligación en Roma, afirma: 
La figura más antigua relativa al instituto de la obligación en el Derecho Romano es la sponsio rito aitiquísimo que se basaba en la fuerza religiosa de un juramento ante los dioses, luego es sustituida en las Doce Tablas por un deber laico fundamentándose en el oportere que era un deber civil reconocido por el ordenamiento y permitía la ejecución civil a través de la legis actio per iudicis arbitrive postulationem.

Haciendo un salto en el tiempo y en la historia, en el ordenamiento jurídico colombiano, el derecho de crédito está regulado por el Código Civil, y lo define así:

Derechos personales o créditos. Derechos personales o créditos son los que sólo pueden reclamarse de ciertas personas que, por un hecho suyo o la sola disposición de la ley, han contraído las obligaciones correlativas; como el que tiene el prestamista contra su deudor por el dinero prestado, o el hijo contra el padre por alimentos. De estos derechos nacen las acciones personales. (Ley 57 de 1887, art. 666)

Como la premisa general de este derecho es la obligación, para el legislador colombiano una persona puede obligarse siempre que sea legalmente capaz, que manifieste su consentimiento no viciado, que el acto o declaración tengan objeto y causa lícitos. (Ley 57 de 1887, art. 1502). Al configurarse lo anterior y existir el acuerdo de voluntades nace la relación jurídica entre las partes. Ahora, se habla de incumplimiento de la obligación cuando falta de cumplimiento estricta y eficaz de la prestación debida por el obligado (deudor) (Universidad Politécnica de Cartagena, 2018).

Para la garantía de este derecho, el mismo ordenamiento jurídico colombiano, establece varias herramientas jurídicas para su protección como la fianza, la hipoteca y la prenda (Ley 57 de 1887, art. 65), y se materializa a través de distintos instrumentos. Pero particularmente, como derecho subjetivo, tiene varias figuras procesales por las cuales se puede exigir la obligación incumplida, entre ellos, en materia civil se destacan el proceso ejecutivo y el nuevo proceso monitorio, que serán estudiados seguidamente.

\section{Proceso Monitorio en la doctrina, la legislación y la jurisprudencia colombiana.}

El Código General del Proceso, trajo dentro de sus innovaciones la figura del proceso monitorio, como un avance y una innovación al sistema 

adelantados en los juzgados civiles municipales de Sincelejo...

procesal, para la garantía expedita, en sede judicial del derecho sustancial que le asiste a un acreedor, en una relación de crédito, para solicitar el pago de una obligación de carácter dineraria cuando carece de un título ejecutivo (Nisimblat \& y Luna, 2016).

Esta figura procesal quedó regulada a partir del artículo 419 de la Ley 1564 de 2012, y está en el catálogo de los procesos declarativos especiales. Este tipo de procesos se caracteriza por su informalidad, no obstante, por tratarse de un proceso declarativo, al tenor de la ley 640 de 2001, para este tipo de procesos se exige como requisito de procedibilidad la conciliación extrajudicial en derecho (Colmenares, 2018). sobre este punto existen varios autores que difieren en su posición, considerando que por ser proceso declarativo si debe tener como requisito de procedibilidad la conciliación extrajudicial, otros, por el contrario, atendiendo su naturaleza, son de la tesis que este proceso, por demás expedito, está exento de este requisito (Caidedo, 2016). Entre ellas se encuentra Rodríguez (2018) quien semana que:

El requisito de la conciliación prejudicial para iniciar un procedimiento monitorio, sí que favorece a la satisfacción del crédito y la descongestión de la justicia. Sin embargo, no debe perderse de vista que el afianzamiento de tal requisito de procedibilidad como herramienta útil, se dará en la medida en la que los usuarios de la administración de justicia se concienticen del adecuado uso que pueden hacer de la conciliación; ya es hora de dejar de verla como un simple paso que cumplir para lograr llegar a instancias litigiosas, para comenzar a entenderla como una verdadera aliada en la solución amistosa de las controversias.

Pero más allá de la discusión procesal, se requiere hacer un abordaje desde el enfoque del derecho de crédito, ya que éste derecho sustancial que es el que se pretende tutelar a través del proceso judicial, también tiene otros mecanismos legales para su protección, y que también tuvieron reformas o adecuaciones en el nuevo sistema procesal introducido por la Ley 1564 de 2012 (Canosa, 2012).

Para Sánchez (2015), el proceso monitorio funde sus orígenes en la legislación europea, y se configuró como una herramienta jurídica agil y eficaz que evitara las demoras de los trámites procesales ordinarios para hacer frente a la mora en la que incurrían los ciudadanos europeos, cuya implementación empezó a partir del 2008. Para el autor, la introducción de esta figura en el ordenamiento jurídico colombiano, supone una 
nueva mirada de la jurisdicción civil y representa una alternativa de solución y materialización del derecho a la tutela judicial efectiva en una relación de crédito donde no existe un documento o título que respalde la obligación. Para el Instituto Colombiano de Derecho Procesal, promotor de esta iniciativa, este proceso tiene como objeto la satisfacción o pago de una obligación de carácter dinerario, con las características propias de una obligación de esta naturaleza, y que su valor esté dentro del rango de menor cuantía (hasta 40 SMLMV).

El Código General del Proceso lo regula de la siguiente manera:

Artículo 419. Procedencia. Quien pretenda el pago de una obligación en dinero, de naturaleza contractual, determinada y exigible que sea de mínima cuantía, podrá promover proceso monitorio con sujeción a las disposiciones de este Capítulo.

En el artículo siguiente (420, CGP), se establecen los requisitos que debe contener la demanda en forma cuando se pretenda hacer ejercicio de esta figura, a saber, los siguientes:

1. Designación del juez al que se dirige.

2. Generales de ley de demandante y demandado, o de sus representantes o apoderados, según sea el caso.

3. Pretensión clara y precisa.

4. Hechos.

5. Manifestación clara, expresa y precisa de no dependencia de una contraprestación a cargo del legitimado en activa (acreedor).

6. Pruebas aportadas o solicitadas.

7. Aporte de los documentos en donde conste la obligación contractual o la manifestación juramentada de la no existencia de los mismos.

8. Direcciones de notificaciones

9. Anexos pertinentes. 

adelantados en los juzgados civiles municipales de Sincelejo...

Para Muñoz (2012), el trámite establecido por el Nuevo Estatuto Procesal en el artículo 421, se puede representar gráficamente de la siguiente manera:

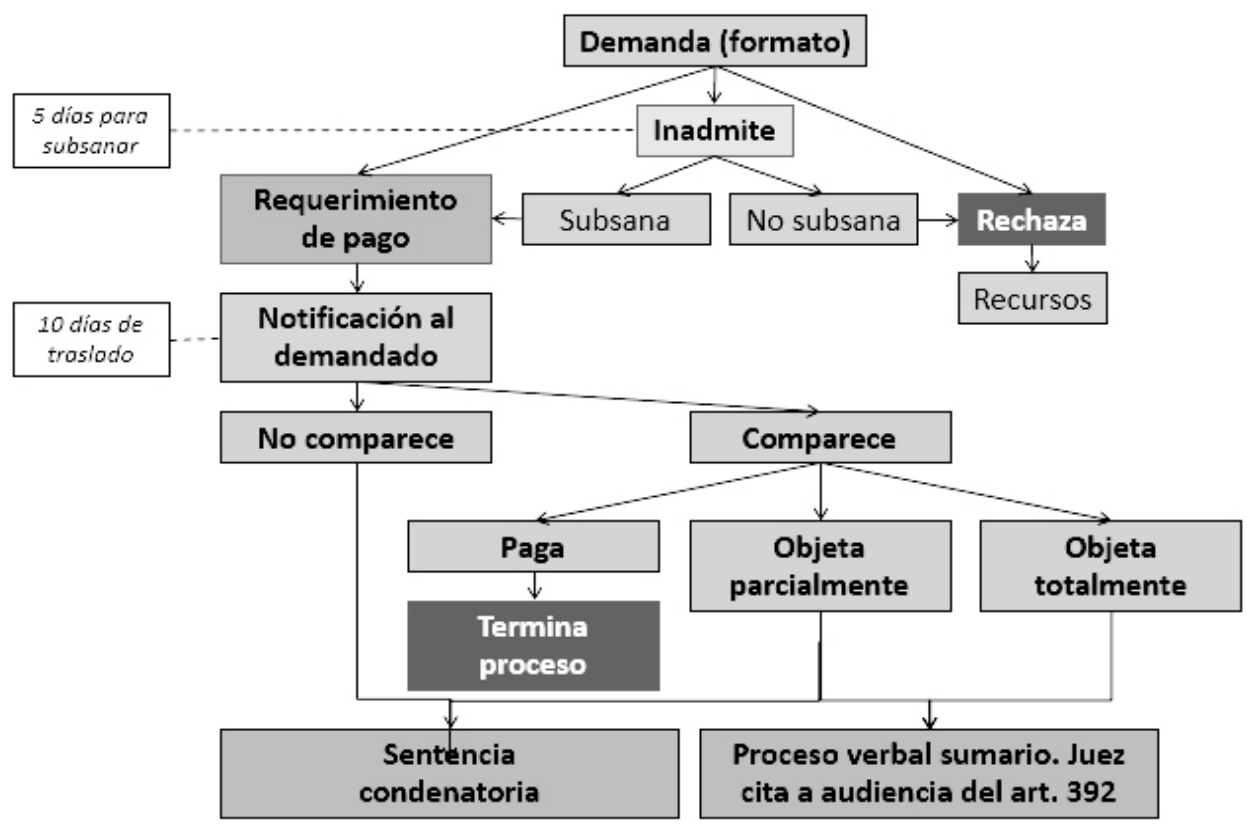

Figura 1. Trámite de los Procesos Monitorios - Art. 421 del CGP.

Fuente: Tomado de: https://munozmontoya.com/2012/10/09/todo-sobre-losprocesos-monitorios-art-419-del-cgp/

Para Nisimblat \& Luna (2017), en este tipo de procesos únicamente se pueden ventilar asuntos, o mejor, obligaciones de carácter dinerario, lo que supone que no se pueden tramitar por ellas obligaciones que revistan la calidad de hacer o no hacer; en otras palabras, solo procede para obligaciones de pagos de sumas de dinero $u$ obligaciones económicas incumplidas.

De otra parte, para Colmenares (2018), al abordar este proceso, empieza por enmarcarlo desde los principios que adopta el Código General del Proceso, desde su artículo $2^{\circ}$. Para el autor, coincidiendo con los anteriores, afirma que:

Con la finalidad de tutelar jurisdiccionalmente de una manera eficaz el derecho de crédito cuando no existe un título ejecutivo, se creó el instrumento denominado: "proceso monitorio" interpretado por el propio legislador 
como "un trámite procesal sencillo a través del cual se facilita la constitución o el perfeccionamiento del título ejecutivo sin necesidad de agotar el trámite del proceso declarativo, siempre que el deudor no plantee oposición.

Ahora, respecto al trámite establecido en el artículo 421 de Código General del Proceso, en su ponencia sobre aspectos prácticos del proceso monitorio, Colmenares (2018), hace un análisis sobre las figuras y etapas procesales que intervienen y se desarrollan en el transcurso del proceso, acotando que respecto de la primera figura procesal que se presenta, oposición, en ella la carga de la prueba está en cabeza del demandante en el evento en que el el demandado se opusiera, sin embargo, en caso contrario, cuando sea el demandado quien alegue hechos o situaciones que puedan generar la extinción de la obligación, le corresponderá aportar las pruebas. Otro aspecto relevante que destaca el autor es el que se refiere a la notificación, señalándose que para preservar la disposición constitucional de observancia del debido proceso, se deberá surtir la fase de notificación descrita en los artículos 291 y 292 de la Ley 1564 de 2012. Acto seguido la fase procesal siguiente es a comparecencia del demandado.

Otra de las particularidades que denota per sé el proceso monitorio es su calidad de proceso declarativo, y como tal debe surtir los trámites procesales y pre-procesales para garantizar su legitimidad. Sobre el particular, Colmenares (2018b) recuerda el contenido de la Ley 640 de 2001 que establece la conciliación como requisitos de procedibilidad en asuntos civiles. De acuerdo al autor, al tenor literal de la norma, el proceso monitorio no quedó excluido de este requisito de conformidad con el artículo 621 del CGP modificatorio de la mencionada Ley 640 de 2001 en su artículo 38. No obstante, al realizarse un juicio de constitucionalidad a la norma, la Corte Constitucional de Colombia, en su Sentencia C - 726 de 2014, señaló que el legislador colombiano, al incluir el proceso monitorio en el nuevo estatuto procesal, con su características y particularidades, tuvo una doble finalidad, (i) materializar el derecho de acceso a la justicia y garantizar el derecho de crédito, y (ii) descongestionar el aparato jurisdiccional del Estado. Ahora bien, como en el sistema colombiano el sistema de interpretación predominante es el sistemático, impone a la praxis jurídica del operador judicial interpretar la disposición que regula al proceso monitorio, obviando el error involuntario cometido por el legislador a no excluir tácitamente este tipo de procesos de los eximidos del 
trámite pre-procesal de la conciliación. No obstante, sobre este particular se hablará más adelante.

Como quiera que el proceso monitorio no es en sí un proceso ejecutivo, para Colmenares (2018c), en curso del proceso monitorio no está facultado al operador judicial ejecutar de manera oficiosa la sentencia que se profiera en dicho proceso, en cualquiera de los dos eventos en que se presente. Sin embargo, a solicitud de parte, sin menester de interponer nueva demanda, se podrá ejecutar haciendo uso del denominado proceso ejecutivo impropio, o del proceso ejecutivo con base en la sentencia judicial.

Finalmente, para este tipo de procesos la norma no admite la interposición de recursos, intervención de terceros, reconvenciones excepciones, o emplazamientos. Lo que sí es posible solicitar el decreto y práctica de medidas previas o pre-cautelativas (Arnedo, y otros, 2016).

\section{Conciliación Extrajudicial en Derecho en Colombia}

En periodos de tiempo moderno, las sociedades de distintas maneras han alternado en particulares formas de administrarse justicia a sí mismas. En diversidad de maneras estas han constituido mecánicas clásicas de proveerse justicia social, estableciendo esquemas procesales ampliamente basados en el ritualismo y la inflexibilidad legal, gestándose así en su mayoría los sistemas clásicamente dispositivos de administración de justicia, que recogen en la actualidad gran parte de las estructuras judiciales de los estados. Es entonces la racionalidad humana la que da forma a los sistemas de administración de justicia, dejando a un lado aspectos de la primitiva violencia en camino a la obtención de derechos. Siendo criterio ordenador de la administración de justicia, debemos mencionar que este es a la vez una aptitud presente en las partes que asumen un conflicto y persiguen su resolución.

De manera alternativa a los sistemas clásicos de administración de justicia, encontramos formas simplificadas de resolver los distintos conflictos en la sociedad como la conciliación extrajudicial en derecho. A la cual debemos decir que, en conjunto con los demás mecanismos alternativos de resolución de conflictos, plantean un camino alternativo para la consecución de subterfugio a los problemas que surgen en medio de la convivencia en sociedad. (Zan, 2004)

Para Silva (2009) al aducir que: "contrario a la creencia normal, la conciliación no es una figura moderna en el Derecho colombiano", resalta el intenso desarrollo normativo y práctico social, a partir de la 
consagración de la Constitución política Colombiana de 1991, pero que esta está presente en Colombia desde los inicios de su vida republicana en el siglo XIX con la promulgación de la ley 13 de 1825. Podemos agregar, que a partir de la promulgación de la Constitución Política de 1991, en Colombia, en referencia a la conciliación extrajudicial en derecho se conceptualiza un marco normativo disperso, que se aglutina finalmente con la ley 640 de 2001 y establece un concepto claro de esta, que recoge su importancia a nivel institucional, procesal y social.

Se le denomina extrajudicial, porque partiendo de ser una forma alternativa a los sistemas de justicia tradicional, se surte por fuera de los procedimientos judiciales del sistema ordinario y general de administración de justicia en Colombia; aunque cabe decir, que está igualmente presente dentro de estos, como etapa procesal correspondiente y necesaria de la mayoría de formas que conoce la justicia ordinaria. La conciliación extrajudicial en derecho, es entonces punto intermedio entre la ciudadanía y la función de administrar justicia por parte del estado, puesto que permite en primer lugar delegar la tan importante labor de integrar equidad ciudadana por medio de la justicia y descongestiona los ya atestados estrados judicial.

En Colombia, se debe decir, que hasta entrado el siglo XXI, aún se tenía por costumbre judicializar los problemas que surjan a diario; esto, a causa de la confianza legítima pero recelada en los medios que representa el estado y el poco merito a lo que no implique coercitividad y presencia de elevados funcionarios que por forzada labor impartan solución a los problemas ciudadanos. Viene ahora a ser la conciliación extrajudicial en derecho, modificador de esa concepción tradicional de judicialización de los problemas por más comunes y simples que se tengan, agitando las bases mismas de la costumbre ciudadana de cómo solucionar sus problemas y cambiando la percepción general de esto al día de hoy.

El establecimiento de la conciliación extrajudicial en derecho, como requisito de procedibilidad, constituye una apuesta importante por modificar la forma en que racionalmente le impartimos solución a los problemas; lo es así porque el estado conmina por intermedio de la ley a que se recurra al dialogo y la gestión simple del conflicto en espacios preparados para ello, en compañía de personal igualmente calificado y con la confianza legítima de que allí también se consigue justicia.

En lo que atañe a la figura de este mecanismo alternativo de solución de conflictos (MASC), la Ley 640 de 2001, en su artículo 38 establece 

adelantados en los juzgados civiles municipales de Sincelejo...

cuando este mecanismo se constituye en requisito de procedibilidad para acudir a la jurisdicción civil. Por supuesto, está contemplada para los procesos declarativos, dentro de los que se encuentra el proceso monitorio, pero tal como se ha señalado anteriormente fue la misma Corte Constitucional la que estableció que la no inclusión del proceso monitorio en las exclusiones del artículo 38 de la Ley 640 de 2001, fue un yerro del legislador al momento de la configuración de la norma, no obstante al hacer un interpretación holística de la misma se entiende que la configuración, la génesis y la teleología de la misma, se considera que el monitorio está exento de este trámite previo.

Zanjada esta discusión jurídica, en la cual algunos autores consideraban que la sola pretensión de que se requiriera la conciliación pre-procesal, desnaturalizaría el proceso monitorio, y en consecuencia el mecanismo alternativo sustituiría al procedimiento judicial, se hace necesario entonces, observar, como se propuso al inicio, el comportamiento estadístico de esta figura en los juzgados civiles municipales de Sincelejo, en la marca temporal comprendida entre los años 2016 y 2017.

\section{Análisis estadísticos de procesos monitorios adelantados en los juzgados civiles municipales de Sincelejo: años 2016 - 2017}

Para el análisis estadístico, iniciaremos con las cifras generales manejadas por los juzgados civiles municipales de Sincelejo durante los años 2016 y 2017. Para ello, tendremos en cuenta los siguientes indicadores, de acuerdo con los informes de la Unidad de Desarrollo y Análisis del Consejo Superior de la Judicatura para los años respectivos:

1. Ingresos y Egresos efectivos y promedio mensual de ingresos.

2. Total Inventario final.

3. Promedios mensuales de ingresos y egresos procesos y tutelas e impugnaciones.

4. Índice de evaluación parcial efectivo.

Así las cosas, tenemos que entre enero de 2016 y diciembre de 2017, ingresaron a los juzgados civiles municipales de Sincelejo nueve mil ciento diez (9110) procesos judiciales, distribuidos como se muestra en la siguiente figura: 
INGRESOS EFECTIVOS

AÑOS 2016 - 2017

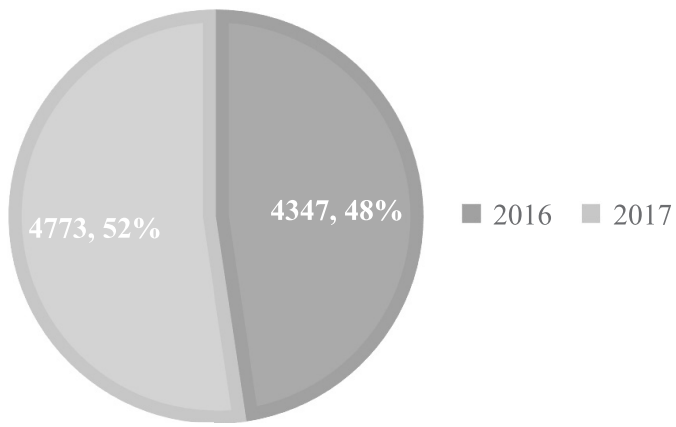

Figura 2. Ingresos Efectivos Juzgados Civiles Municipales de Sincelejo 2016 2017.

Fuente: Elaboración propia.

Para el año 2016, a los juzgados civiles de Sincelejo ingresaron cuatro mil trescientos cuarenta y siete (4347), distribuidos por juzgados como se muestra.

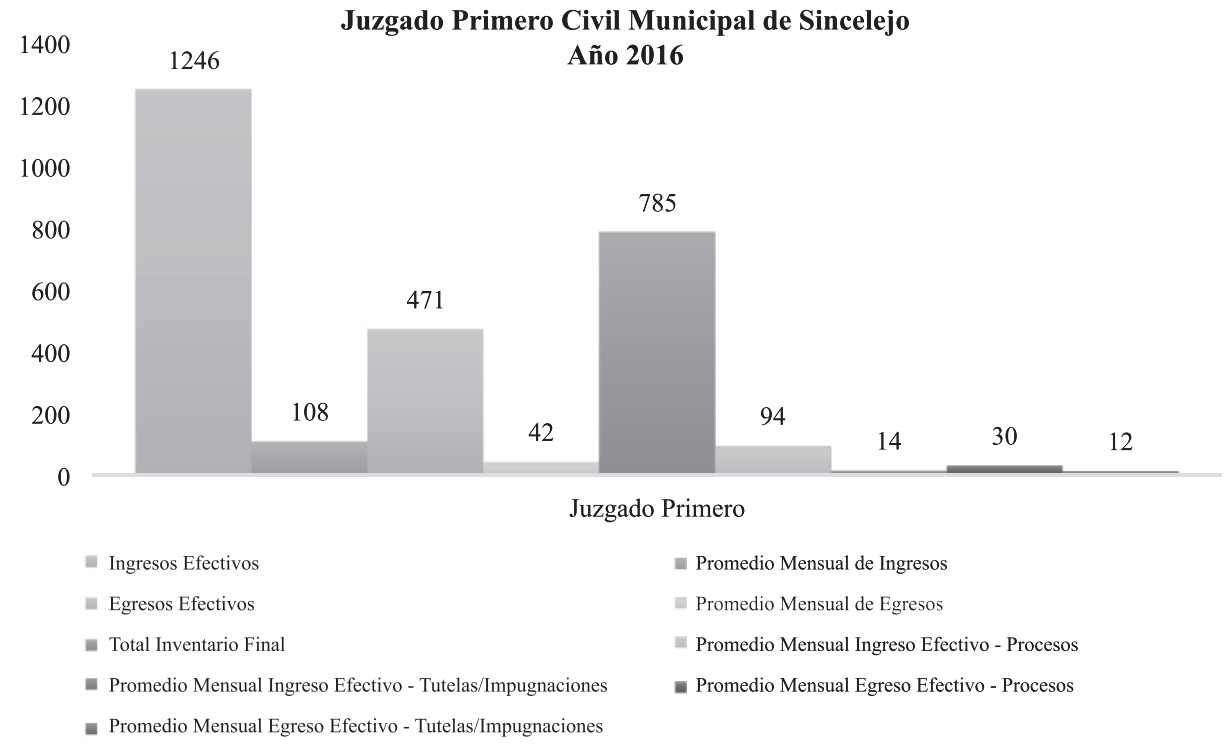

Figura 3. Ingresos Efectivos Juzgado Primero Civil Municipal de Sincelejo 2016. Fuente: Elaboración propia. 
Incidencia del proceso monitorio como garantía del derecho de crédito en los procesos adelantados en los juzgados civiles municipales de Sincelejo...

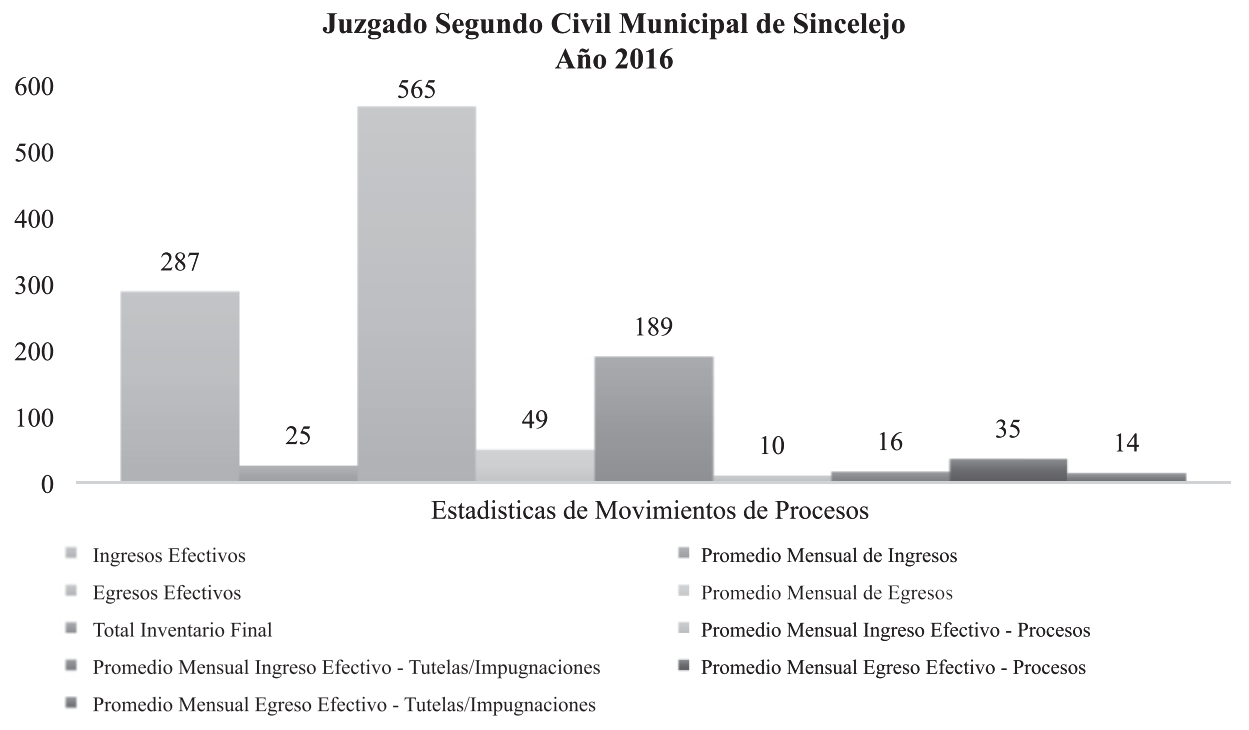

Figura 4. Ingresos Efectivos Juzgado Segundo Civil Municipal de Sincelejo 2016.

Fuente: Elaboración propia.

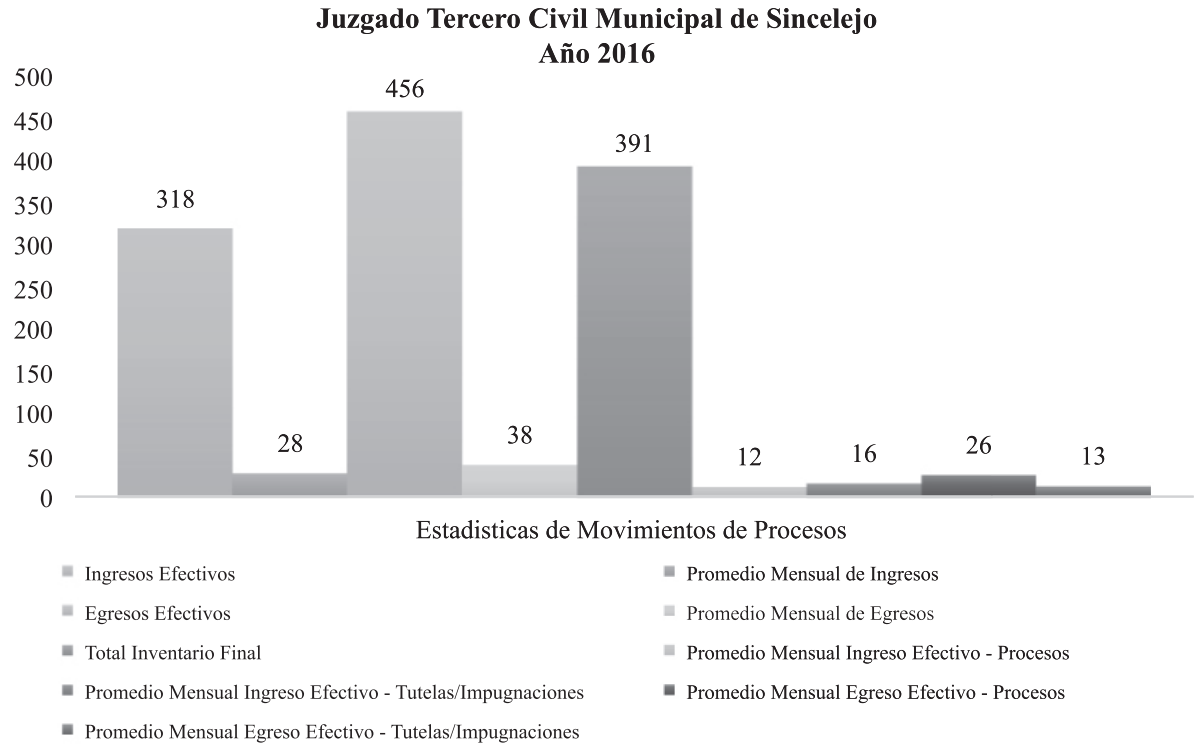

Figura 5. Ingresos Efectivos Juzgado Primero Civil Municipal de Sincelejo 2016. Fuente: Elaboración propia. 


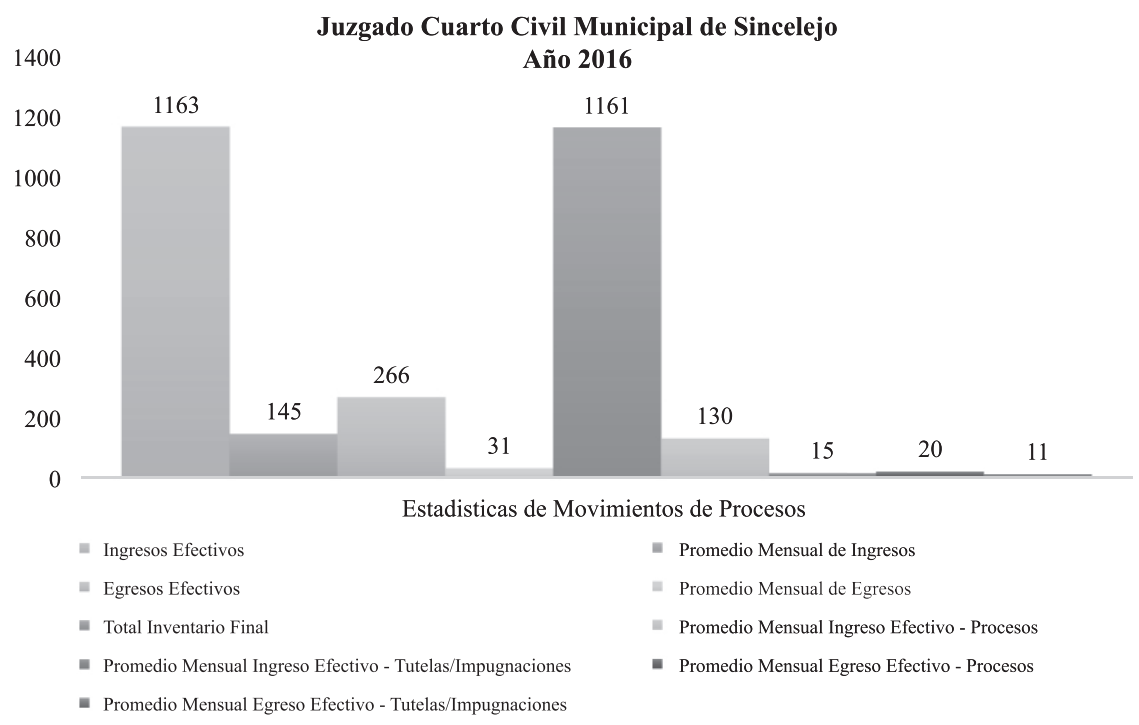

Figura 6. Ingresos Efectivos Juzgado Cuarto Civil Municipal de Sincelejo 2016

Fuente: Elaboración propia

De conformidad con la información suministrada por el Sistema de Estadísticas de la Rama Judicial, el índice de ejecución de los juzgados civiles municipales de Sincelejo para el año 2016 estuvo en 70\%, mientras que para el 2017 hubo un incremento del 12\% obteniendo un índice de evacuación parcial efectivo del 82\%. Para el año 2017, a los juzgados civiles de Sincelejo ingresaron cuatro mil setecientos setenta y tres (4773), distribuidos por juzgados como se muestra:

1000

783

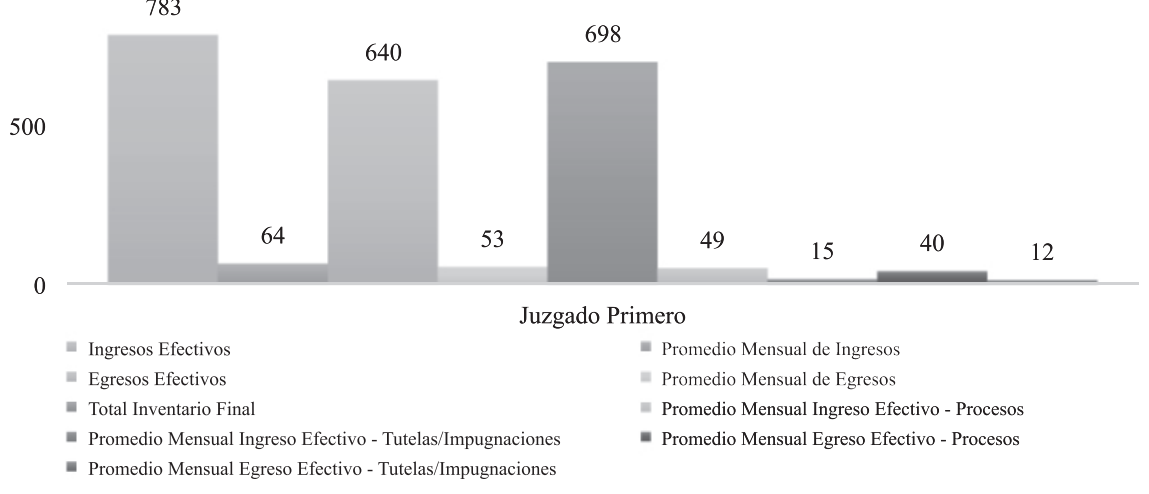

- Promedio Mensual de Ingresos

= Promedio Mensual de Egresos

= Promedio Mensual Ingreso Efectivo - Procesos
Juzgado Primero Civil Municipal de Sincelejo

Año 2017

Figura 7. Ingresos Efectivos Juzgado Primero Civil Municipal de Sincelejo 2017.

Fuente: Elaboración propia. 
Incidencia del proceso monitorio como garantía del derecho de crédito en los procesos adelantados en los juzgados civiles municipales de Sincelejo...

1000

\section{Juzgado Segundo Civil Municipal de Sincelejo}

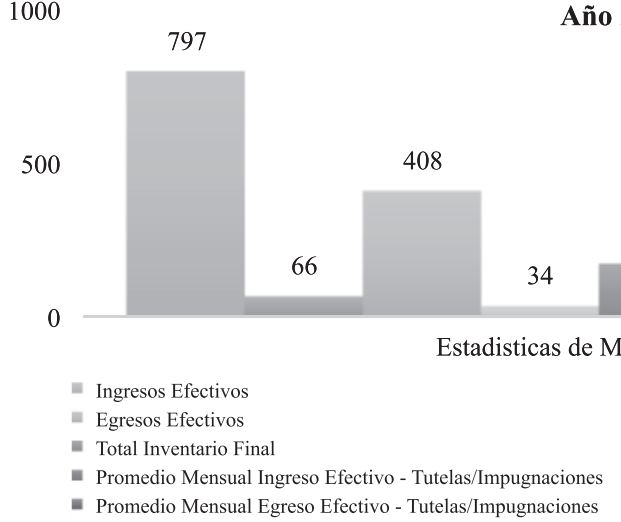

172

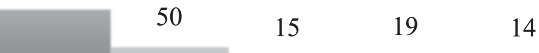

Figura 8. Ingresos Efectivos Juzgado Segundo Civil Municipal de Sincelejo 2017.

Fuente: Elaboración propia.

\section{Juzgado Tercero Civil Municipal de Sincelejo \\ Año 2017}

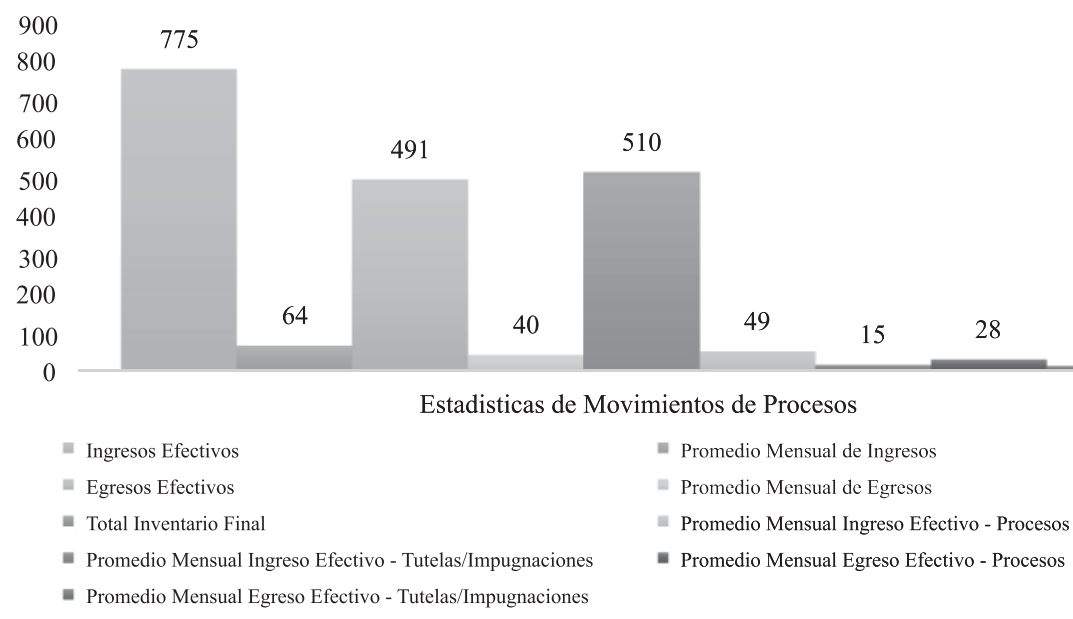

Figura 9. Ingresos Efectivos Juzgado Primero Civil Municipal de Sincelejo 2017.

Fuente: Elaboración propia. 
1200

1000

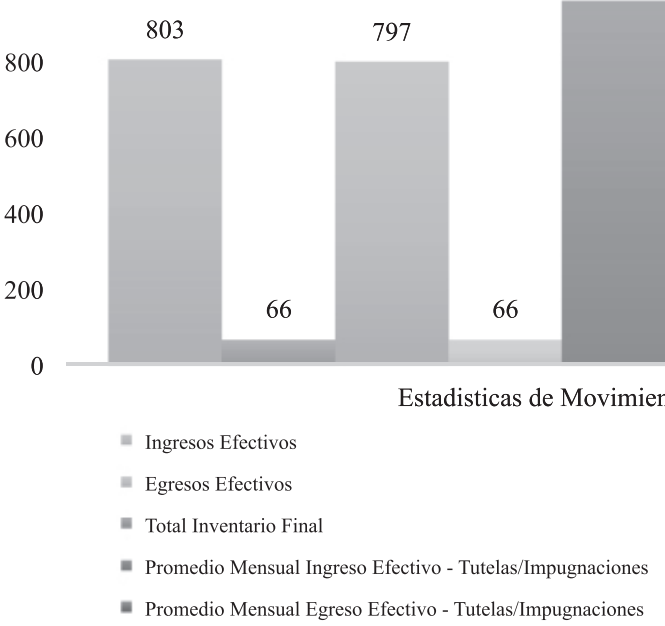

Juzgado Cuarto Civil Municipal de Sincelejo

Año 2017

958

49

$17 \quad 50$

16

Figura 10. Ingresos Efectivos Juzgado Cuarto Civil Municipal de Sincelejo 2017.

Fuente: Elaboración propia.

\section{Juzgado Quinto Civil Municipal de Sincelejo}

\section{Año 2017}

1000

826

838

848

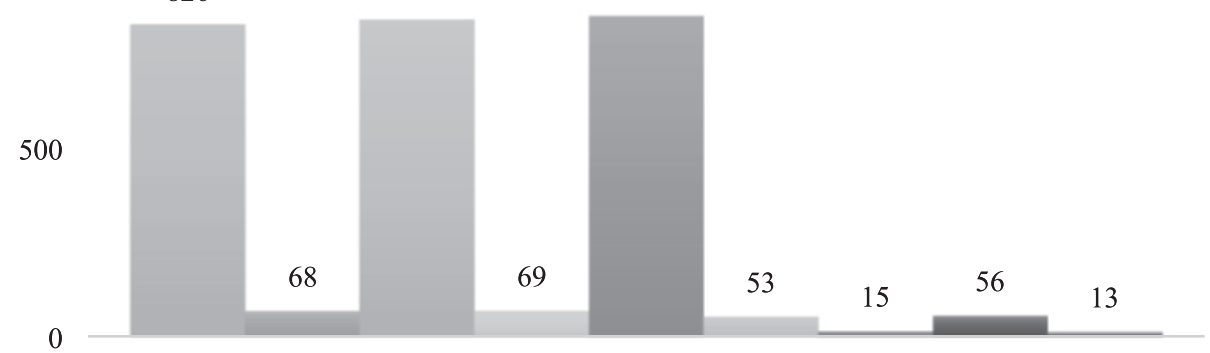

Estadisticas de Movimientos de Procesos

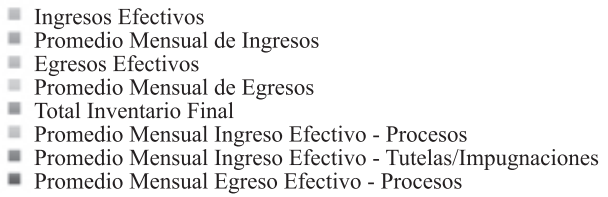

Figura 11. Ingresos Efectivos Juzgado Quinto Civil Municipal de Sincelejo 2017.

Fuente: Elaboración propia. 
Incidencia del proceso monitorio como garantía del derecho de crédito en los procesos adelantados en los juzgados civiles municipales de Sincelejo...

Juzgado Sexto Civil Municipal de Sincelejo

Año 2017

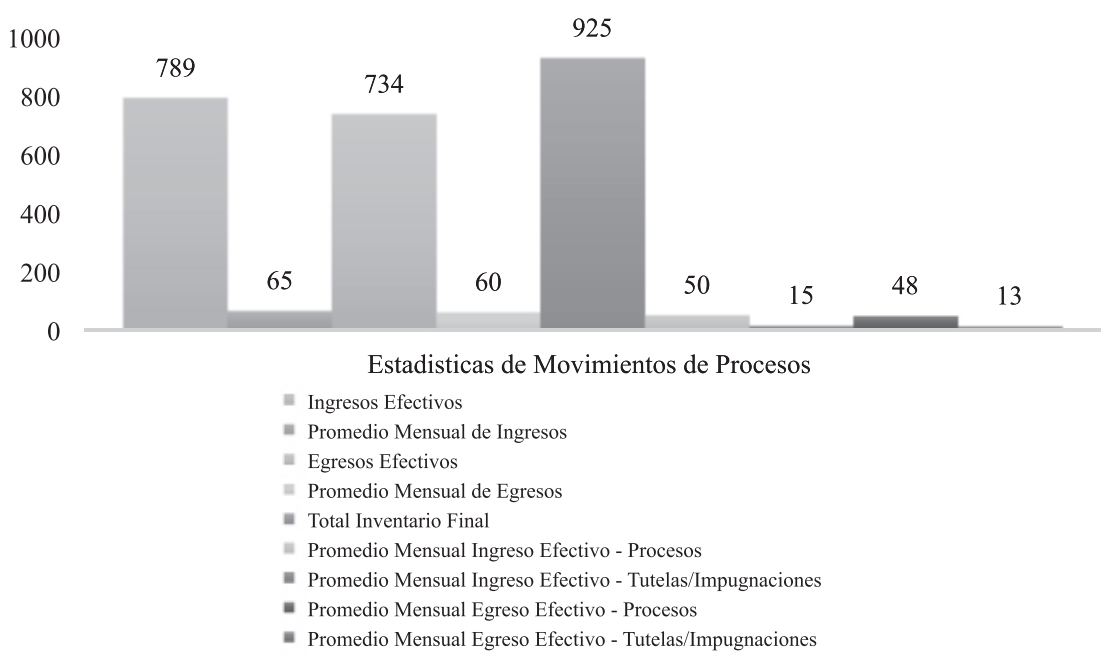

Figura 12. Ingresos Efectivos Juzgado Sexto Civil Municipal de Sincelejo 2017.

Fuente: Elaboración propia.

Procesos monitorios adelantados en los juzgados civiles municipales de Sincelejo durante los años 2016 - 2017

De acuerdo a los libros radicadores de los juzgados civiles municipales de Sincelejo, que fueron revisados para la investigación, se identificaron que en la marca temporal estudiada se tramitaron treinta (30) procesos monitorios, distribuidos así:

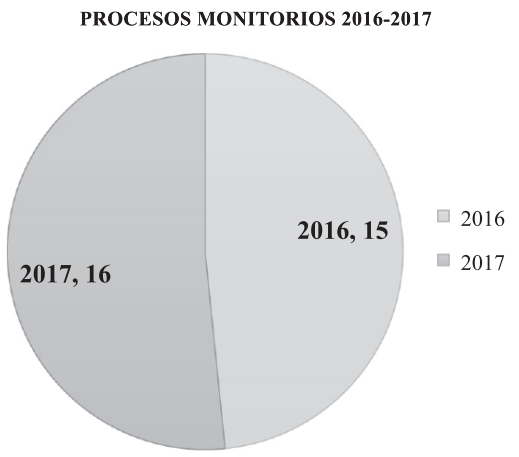

Figura 13. Procesos Monitorios Juzgados Civiles Municipales de Sincelejo 20162017.

Fuente: Elaboración propia. 


\section{Estadísticas por Juzgados \\ PROCESOS MONITORIOS POR JUZGADOS 2016-2017}

\begin{tabular}{|r|r|r|r|}
\hline & \multicolumn{1}{c|}{5} & & \\
\hline
\end{tabular}

Figura 14. Procesos Monitorios por Juzgados Civiles 2016-2017

Fuente: Elaboración propia.

De los cuatro (4) procesos monitorios adelantados en el año 2016 en el Juzgado Primero Civil Municipal de Sincelejo, dos (2) están en estado de admitidos, uno (1) está en liquidación de crédito y uno (1) en ejecución. Para el año 2017 se adelantaron cuatro (4) monitorios de los cuales uno (1) fue rechazado por no subsanar, uno (1) está la terminación del proceso y la cancelación de la medida cautelar por pago de la obligación, uno (1) no admitido y uno (1) remite a juzgado civil de Cartagena.

En el único proceso adelantado en el Juzgado Segundo Municipal de Sincelejo solamente se obtuvo información de radicación y admisión del proceso.

En el Juzgado Tercero Civil Municipal de Sincelejo, se presentó en el 2016 un (1) solo proceso que está en sentencia que condena al demandado. Para el 2017 de presentaron dos (2), en uno (1) se confirma providencia de mandamiento de pago y decreto de medida cautelar, y uno (1) se realizó audiencia y se dictó sentencia.

En el Juzgado Cuarto Civil Municipal de Sincelejo, en 2016 se presentaron cuatro (4) procesos, en uno (1) se da por terminado el proceso por no comparecencia, uno (1) se dictó sentencia y condena al pago de la obligación. En uno (1) se encuentra en auto que se abstiene 

adelantados en los juzgados civiles municipales de Sincelejo...

de decretar medida cautelar y en uno (1) se condena al demandado al pago de la obligación. Para el 2017 se presentaron dos (2) procesos. Uno (1) se retiró la demanda y en otro se remitió a otro juzgado por falta de competencia.

En el Juzgado Quinto Civil Municipal de Sincelejo, en 2016 no se presentaron procesos monitorios. En 2017 se presentaron 4. De ellos uno (1) prosperó excepción de mérito y se dio por terminado el proceso, uno (1) admitido, uno (1) fijación de audiencia y uno (1) inadmitido.

En el Juzgado Sexto Civil Municipal de Sincelejo, se presentaron en 2016 cinco (5) monitorios, uno (1) se dio por terminado por desistimiento tácito, uno (1) inadmitido, uno (1) retiro de la demanda, uno (1) declaración de incompetencia y uno (1) expide sentencia condenatoria. Para el 2017 se presentaron cuatro (4) monitorios, en uno (1) se libró mandamiento de pago, y tres (3) fueron rechazados.

\section{Conclusiones}

Una vez desarrollada la presente investigación, se pudo, en primer momento conceptualizar el derecho de crédito con fundamento en las disposiciones del ordenamiento jurídico colombiano, que lo establece como la relación jurídica que surge del acuerdo de voluntades entre dos personas por medio de la cual una se obliga respecto de otra al pago o reconocimiento en dinero de una obligación económica, cuya característica es la correlatividad por configurarse tanto en derecho subjetivo a favor del acreedor, como en deber jurídico para el deudor. Así mismo, como derecho subjetivo, tiene instrumentos y garantías jurídicas y judiciales para su protección.

De la misma manera se logró desarrollar la figura del proceso monitorio a partir de la Ley 1564 de 2012, que lo instituye como una herramienta novedosa que busca la protección real y material del derecho de crédito cuando el acreedor carece de título ejecutivo para hacer efectiva una obligación dineraria, aportando a la descongestión de los despachos judiciales debido a sus características de informalidad, celeridad y eficacia.

Se logró describir la conciliación extrajudicial en derecho en el ordenamiento jurídico colombiano, a partir de la Ley 640 de 2001, que la introduce como un mecanismo alternativo de solución de conflictos y la propone como requisito de procedibilidad para el ejercicio judicial, particularmente para los procesos civiles declarativos a partir del artículo 
38, exceptuándose el proceso monitorio conforme al criterio de la Corte Constitucional.

Al realizar el análisis los procesos monitorios adelantados en los juzgados civiles municipales de Sincelejo durante los años 2016 y 2017, se encontró que muy a pesar de ser una figura nueva, su utilización ha sido significativa, no obstante no logra per sé, garantizar el derecho de crédito, teniéndose de esta manera que su incidencia en cuanto a la protección de este derecho subjetivo es baja, pues la mayoría de los procesos adelantados, tal como se observó en las estadísticas resultaron inadmitidos o rechazados. Lo que nos hace proponer la revisión de la efectividad de esta figura.

\section{Referencias}

Alterino, A., Ameal, O., \& López, R. (1995). Derecho de Obligaciones: Civiles y Comerciales. Michigan : Abeledo-Perrot.

Arnedo, M., Brito, J., Díaz:, J., Gil, D., Godín, A., Hernández, D., . . Narváez, M. (Diciembre de 2016). El Proceso Monitorio: instrumento procesal a la mano del cuidadano en desarrollo eficaz del derecho fundamental de acceso a la justicia. Obtenido de Revista de Derecho Procesal Contemporáneo - ISSN 2463-0549 Edición 3 Julio - Diciembre de 2016, pp. 150-167. : publicacionesicdp.com/index.php/revista-semilleros-icdp/article/download/439/pdf

Código Civil de Colombia. (25 de Mayo de 2018). Ley 57 de 1887, Código Civil Colombiano. Obtenido de http://www.alcaldiabogota.gov. co/sisjur/normas/Normal.jsp?i=39535

Colmenares, C. (25 de Mayo de 2018). Aspectos prácticos del Proceso Monitorio. Obtenido de http://colmenaresabogados.com/files/ PONENCIA\%20DEFINITIVA\%20ASPECTOS\%20PRACTICOS\%20 DEL\%20PROCESO\%20MONITORIO.pdf

Colmenares, C. (2018). El proceso monitorio en el Código General del Proceso en Colombia: Ley 1564 de 2012. Obtenido de https://letrujil. files.wordpress.com/2013/09/14carlos-alberto-colmenares.pdf

Jiménez, J. (Septiembre de 2013). La obligación civil romana y las garantías de derecho de crédito. Revista Judicial Costa Rica, $N^{\circ} 109$. Obtenido de http://www.corteidh.or.cr/tablas/r31073.pdf 

adelantados en los juzgados civiles municipales de Sincelejo...

Jurídica, E. (25 de Mayo de 2018). Enciclopedia Jurídica. Obtenido de http://www.enciclopedia-juridica.bizl4.com/d/derecho-de-cr\%C3\%A9dito/derecho-de-cr\%C3\%A9dito.htm

Muñoz, J. (9 de Octubre de 2012). Todo sobre los Procesos Monitorios (Art. 419 del CGP). Obtenido de https://munozmontoya. com/2012/10/09/todo-sobre-los-procesos-monitorios-art-419del-cgp/

Nisimblat, N., \& Luna, F. (2017). El Proceso Monitorio: Una innovación judicial para el ejercicio de derechos crediticios. Obtenido de Revista Jurídica MArio Alario D’Filippo. Cartagena (Colombia) Vol. IX. Nº 17: 154-168, enero-junio 2017: http://revistas.unicartagena.edu. co/index.php/marioalariodfilippo

Rodríquez, M. (25 de Mayo de 2018). La Conciliación, una aliada en la satisfacción del crédito. Obtenido de http://procesal.uexternado. edu.co/pR0c3-3xT3rNaD0-U3C/wp-content/uploads/2017/02/ LA-CONCILIACI\%C3\%93N-UNA-ALIADA-EN-LA-SATISFACCI\%C3\%93N-DEL-CR\%C3\%89DITO.pdf

Sánchez, P. (2015). Hacia un Proceso Monitorio en Colombia. Obtenido de Justicia, 28, 139-150: http://www.scielo.org.co/pdf/just/n28/ n28a09.pdf

Silva, P. (11 de Agosto de 2009). Desarrollo de la conciliación a partir de la Constitución de 1991. Obtenido de https://journal.poligran.edu. co/index.php/panorama/article/viewFile/215/195

Ternera, F., \& Mantilla, F. (25 de Mayo de 2018). El concepto de Derechos Reales. Obtenido de Revista de Derecho Privado 2006 [en linea]: http://www.redalyc.org/pdf/3600/360033184003.pdf

Universidad Politécnica de Cartagena. (25 de Mayo de 2018). LECCIÓN $8^{a}$. EL DERECHO DE CRÉDITO U OBLIGACIÓN (II). . Obtenido de http://ocw.bib.upct.es/pluginfile.php/11989/mod_resource/ content/3/LECCION-08.2.pdf

Zan, J. d. (2004). La etica los derechos y la Justicia. Montevideo, Uruguay: Fundacion Konrad Adenauer Stifstung E.V. 